\title{
ASPECTOS PARTICULARES DA CHAMADA JUDICIALIZAÇÃO DA SAÚDE
}

\author{
Specific aspects of the so-called health judicialization
}

\begin{abstract}
Sueli Gandolfi Dallari*
Muito se tem publicado a respeito da chamada "judicialização da saúde", tanto no Brasil como internacionalmente. Com certeza esse aumento expressivo do número de reivindicações judiciais do direito aos cuidados de saúde, sobretudo ao acesso a medicamentos e tratamentos médicos, é devido principalmente à expansão da linguagem dos direitos humanos e ao novo constitucionalismo. De fato, com a Declaração Universal dos Direitos Humanos, de 1948, começa a ser definida uma nova concepção do próprio Direito, que - no dizer de Dalmo Dallari - "exclui as construções formais desprovidas de base social para sua legitimação e voltadas à garantia de privilégios mascarados de direitos".(1) Dissemina-se, então, a compreensão de que: "um direito humano é alguma coisa da qual nenhum ser humano pode ser despojado sem grave afronta à Justiça".(2) $E$ tal entendimento encontra uma resposta imediata na prática e na doutrina jurídica, afirmando-se que nada que tenha alguma importância jurídica fica fora do alcance das disposições constitucionais e, mais importante, que os direitos assegurados pela Constituição devem ser efetivamente realizados.
\end{abstract}

A questão é contudo complexa, pois encontrar os mecanismos capazes de assegurar a realização dos direitos declarados - que têm ao mesmo tempo características que decorrem do tradicional direito civil, individual, do direito coletivo, que privilegia a igualdade, e do novíssimo direito "difuso", cultural, que valoriza sobretudo a solidariedade, dependendo diretamente do nível de desenvolvimento das sociedades e dos Estados - exige importantes adaptações nos modos de interpretar a legitimidade das normas, tanto em sua origem quanto em sua aplicação. Isso implica, por exemplo, assegurar que a democracia será

\footnotetext{
* Coordenadora Científica, Núcleo de Pesquisas em Direito Sanitário da Universidade de São Paulo (NAP-DISA/USP). Professora Titular, Faculdade de Saúde Pública, Universidade de São Paulo (FSP/ USP). Professeur Invitée, Faculté de Droit, Université de Paris X - Nanterre, France $(2007,2008,2009$, 2010, 2011 e 2012); Professeur Invitée, Faculté de Droit, Université de Nantes, France (2002, 2003 e 2006); Tinker Professor, School of International and Public Affairs, Columbia University, USA (1995). São Paulo/SP - Brasil. E-mail: sdallari@usp.br

${ }^{1}$ Cf. DALLARI, D.A. A Constituição na vida dos povos: da idade média ao século vinte e um. São Paulo: Saraiva, 2010. p.289

${ }^{2}$ Cf. CRANSTON, M. O que são Direitos Humanos? São Paulo: DIFEL, 1979. p. 68
} 
especialmente valorizada em todos os momentos da implementação de qualquer política pública destinada a realizar direitos e mesmo quando do controle judicial dessa política.

Ora, tais exigências revelam a inadequação e mesmo a impossibilidade de usar apenas os grandes enunciados constitucionais para a definição do direito, sendo necessário atentar para uma infinidade de critérios normativos. Eles são encontráveis no próprio texto, pois, como ensina Canotilho, a Constituição não mais se limita a

impor ao legislador a prossecução do interesse público, do bem comum, do aumento da qualidade da vida, com base em diretivas tão vagas como a ideia de justiça, de solidariedade ou de direito. Ela define, mais ou menos detalhadamente, os fins do Estado, os princípios materiais norteadores da sua realização e as tarefas dos órgãos estatais. ${ }^{(3)}$

Mas também a legislação ordinária e os atos normativos da Administração, tanto os propriamente administrativos quanto aqueles essencialmente públicos, oferecem critérios indispensáveis para orientar a realização dos direitos complexos da contemporaneidade.

A experiência brasileira de controle judicial em saúde revela com clareza as contradições próprias dos momentos de mudança de paradigmas. Convém lembrar que, ao convocar a audiência pública no Supremo Tribunal Federal (STF), objetivando obter subsídios para o julgamento de ações que tramitam naquela alta corte, em maio de 2009, o Ministro Presidente salientou que todas as considerações apresentadas poderiam ser utilizadas para a instrução de qualquer processo no âmbito do STF e também reunidas e disponibilizadas aos juízos e tribunais que o solicitassem. Almejava ele que as informações colhidas pudessem influenciar as decisões do próprio Tribunal e, também, as decisões judiciais de todo o país. E seu voto, apresentado em 17 de março de 2010, ${ }^{(4)}$ considera as experiências e os dados colhidos na Audiência Pública - Saúde para apresentar parâmetros para as decisões judiciais em matéria de fornecimento de medicamentos pelo sistema público de saúde.

Esses parâmetros, já analisados em excelente artigo de Marco Aurélio Antas Torronteguynesta Revista, sugerem que o julgador utilize a seguinte grade decisória:

1. verificar se existe política pública que diga respeito à prestação de saúde pleiteada no caso concreto;

2. na hipótese de que não haja a política estatal específica, o Judiciário deve considerar:

${ }^{3}$ Cf.CANOTILHO, J.J.G. Constituição dirigente e vinculação do legislador. Coimbra: Coimbra Ed., 1982. p.249

${ }^{4}$ SUPREMO TRIBUNAL FEDERAL. STA 175 - Agr / CE. Disponível em: <http://redir.stf.jus.br/ paginadorpub/paginador.jsp?docTP=AC\&docID=610255>. Acesso em: 28 abr. 2013. 
(a) a existência de vedação legal para o fornecimento do medicamento, ou seja, os juízes devem verificar se o medicamento possui registro na Agência Nacional de Vigilância Sanitária (Anvisa);

(b) a existência de decisão do SUS de não fornecer o medicamento, expressa em Protocolos Clínicos e Diretrizes Terapêuticas do Sistema Único de Saúde (SUS) atualizados;

(c) se o medicamento encontra-se em fase de testes clínicos na indústria farmacêutica;

(d) se o tratamento alternativo oferecido pelo sistema público é adequado para o caso específico do paciente;

(e) se o Executivo comprovou que haveria grave lesão à ordem, à economia, à saúde e à segurança públicas na hipótese de concessão da tutela jurisdicional pretendida pelo paciente. Nesse voto o Ministro Gilmar Mendes insiste em que nenhum dos parâmetros apresentados é irrecorrível, mas que nas hipóteses suscitadas é imprescindível que haja instrução processual, com ampla produção de provas, o que poderá configurar-se um obstáculo à concessão de medida cautelar.

A contradição - reveladora da inadequação do paradigma anterior e da ainda incipiente instalação do atual - ${ }^{(5)}$ pode ser exemplificada nos estudos que servem de base ao debate deste número da Revista de Direito Sanitário. Assim, os trabalhos de Alexandra Boing, Neusa Sens Bloemer, Claudia Roeslere Simone Fernandes, no Estado de Santa Catarina, e de Karina Alves Ramose Anísia da Soledade Dias Ferreira, em Minas Gerais, mostram claramente que não tem havido muita preocupação entre os julgadores com os parâmetros para as decisões judiciais em matéria de fornecimento de medicamentos pelo sistema público de saúde. Verificou-se, por exemplo, que medicamentos cujo fornecimento ficou a cargo dos Municípios, em conformidade com a política nacional de saúde adotada em 2002 e reforçada em $2006,{ }^{(6),(7)}$ foram fornecidos pelo Estado por determinação judicial. Foi possível ver, também, que mais de uma entre dez solicitações judiciais de medicamento atendidas $(10,71 \%)$ referem-se a drogas cujo uso naquela patologia não era recomendado pela bula do laboratório fabricante, ou seja, tratava-se de uso não aprovado pelo órgão sanitário. ${ }^{(8)}$ Esses resultados indicam que os juízes eventualmente ainda não levam em conta os parâmetros propostos naquela audiência pública.

\footnotetext{
${ }^{5}$ KUHN, T. S. La structure des révolutions scientifiques. Paris: Flammarion, 1983.

${ }^{6}$ BRASIL. MINISTERIO DA SAUDE. Secretaria de Assistência à Saúde. Regionalização da Assistência à Saúde: aprofundando a descentralização com equidade no acesso. Norma Operacional da Assistência à Saúde: NOAS -SUS. Ministério da Saúde Brasília, 2001.

${ }^{7}$ BRASIL. MINISTERIO DA SAUDE. Secretaria Executiva. Diretrizes Operacionais dos Pactos pela Vida: em defesa do SUS e de Gestão. Brasília: Ministério da Saúde, 2006.

${ }^{8}$ BRASIL. Resolução RDC n 47, de 8 de setembro de 2009. "Estabelece regras para elaboração, harmonização, atualização, publicação e disponibilização de bulas de medicamentos para pacientes e para profissionais de saúde". Diário Oficial [da] Republica Federativa do Brasil, Brasília, DF, 9 set. 2009. Disponível em: <http://portal2.saude.gov.br/saudelegis/leg_norma_pesq_consulta.cfm> Acesso em: 23 nov. 2010.
} 
Entretanto, os estudos já referidos, como também aquele apresentado por Mário Scheffer, mostram que há necessidade de evolução legislativa e administrativa em decorrência dessa mudança de paradigma que, valorizando os direitos humanos, instaura o neoconstitucionalismo. É preciso que os parlamentares estejam atentos às necessidades dos sistemas de saúde promovendo a indispensável adequação legislativa, sempre buscando respeitar os mecanismos democráticos que devem informar o processo legislativo. Isso é verdade também em relação aos administradores públicos, profissionais da área da saúde, que devem conhecer muito bem sua especialidade, tendo clareza de que ela serve à garantia de um direito e se preocupar, portanto, em fornecer todas as informações que foram relevantes para determinar sua escolha técnica. $\dot{E}$ indispensável que todas as suas decisões sejam amplamente motivadas para permitir o exame de sua adequação às exigências constitucionais e legais aplicáveis. Porém, é necessário, sobretudo, reconhecer que o poder normativo desse Estado contemporâneo pertence igualmente aos órgãos e mecanismos que asseguram a participação direta do povo na definição e o contínuo controle popular dos atos de implementação das políticas públicas. Isso significa a existência de uma outra esfera de poder normativo, que talvez possa ser denominada de eminentemente pública. É preciso, portanto, que o julgador seja capaz de identificar não apenas os argumentos que têm como base atos legislativos em sentido próprio, mas também aqueles que se originam no poder normativo da Administração, e ainda os que têm fundamento no poder normativo propriamente público, derivado da efetiva participação das pessoas na definição e na realização do direito à saúde. E se, na atualidade, esse comportamento deve caracterizar a realização de qualquer direito, ele é indispensável à execução do direito à saúde - ao mesmo tempo um direito individual, coletivo e difuso, que exige a apreensão no processo judicial do verdadeiro sentido do conceito de saúde existente em certa comunidade.

Em suma, os aspectos particulares da chamada judicialização da saúde abordados neste debate ampliam o horizonte do tema, aportando indícios de caminhos a serem percorridos para a justa realização do direito de todos à saúde.

\section{Referências}

BRASIL. MINISTÉRIO DA SAÚDE. Secretaria de Assistência à Saúde. Regionalização da Assistência à Saúde: aprofundando a descentralização com equidade no acesso. Norma Operacional da Assistência à Saúde: NOAS-SUS. Brasília-DF: Ministério da Saúde, 2001.

Secretaria Executiva. Diretrizes Operacionais dos Pactos pela Vida: em defesa do SUS e de Gestão. Brasília: Ministério da Saúde, 2006.

CANOTILHO, J.J.G. Constituição dirigente e vinculação do legislador. Coimbra: Coimbra Ed., 1982. 
CRANSTON, M. O que são direitos humanos? São Paulo: DIFEL, 1979.

DALLARI, D.A. A Constituição na vida dos povos: da idade média ao século vinte e um. São Paulo: Saraiva, 2010.

KUHN, T. S. La structure des révolutions scientifiques. Paris: Flammarion, 1983. 